\section{Acute abdomen as complication of a knee arthroscopy: A case report}

\author{
Jurin Martic Ana ${ }^{1 *}$, Nenad Vidanec ${ }^{1}$, Joško Smilović \\ Matija Mavrić2 ${ }^{2}$, Miljenko Novak ${ }^{3}$ and Petra Mustač Jambrešić ${ }^{3}$
}

\author{
${ }^{1}$ Department of Anesthesiology, Reanimatology and Intensive Care with ICU; County Hospital \\ Čakovec, Croatia \\ ${ }^{2}$ Department of Traumatology, County Hospital Čakovec, Croatia \\ ${ }^{3}$ Department of Radiology and Ultrasound, County Hospital Čakovec, Croatia
}

\section{Abstract}

\begin{abstract}
A knee arthroscopy in spinal anaesthesia was performed on a 67 years old male patient. During the procedure the patient was hemodynamically stable, until he suddenly turned pale and started complaining of severe pain in lower abdomen with signs of guarding. The procedure was finished as urgently as possible and after releasing the tourniquet we noticed significant difference in volume of the leg, with redness distal to tourniquet. Urgent lab results were essentially unremarkable and the patient was sent for the urgent radiological diagnostics.
\end{abstract}

$\mathrm{CD}$ of the left leg described fluid in the soft tissues of the thigh, scrotum, and abdomen; and the unenhanced CT of the abdomen showed free fluid along the entire femoral shaft of the left thigh, extending towards pelvis and abdomen to perihepatic and perisplenic space, and retroperitoneum, with gas bubbles tracking along anterior aspect of the left thigh into the left retroperitoneum.

He was admitted to the ICU, and within few hours all symptoms have resolved and his further recovery was without complications.
More Information

${ }^{*}$ Address for Correspondence: Ana Jurin Martić, County Hospital Čakovec, Ivana Gorana Kovačića 1e, HR-40000 Čakovec, Croatia, Email: jurinana@gmail.com

Submitted: November 21, 2020 Approved: December 21, 2020 Published: December 22, 2020

How to cite this article: Jurin Martic $A$, Vidanec N, Smilović J, Mavrić M, Novak M, et al. Acute abdomen as complication of a knee arthroscopy: A case report. Arch Surg Clin Res. 2020; 4: 051-053.

DOI: 10.29328/journal.ascr.1001054

Copyright: (c) 2020 Jurin Martic A, et al. This is an open access article distributed under the Creative Commons Attribution License, which permits unrestricted use, distribution, and reproduction in any medium, provided the original work is properly cited.

Keywords: Arthroscopy complications; Acute abdomen; Knee arthroscopy

Check for updates

OPEN ACCESS

\section{Introduction}

Knee arthroscopy is a safe operation technique with approximately $1 \%$ complication rate [1]. The most common are pyogenic arthritis, deep vein thrombosis and pulmonary embolism [1]. Fluid extravasation is expected in subcutaneous tissue and around entry portals for arthroscopic tools. In our case, extravasation of irrigation fluid happened in upper thigh, scrotum, retroperitoneal and intraperitoneal space, despite the inflated tourniquet. There are only a few available cases in literature, where the extravasation of the irrigation fluid was mostly limited by inflated tourniquet or was present only below the knee [2,3].

\section{Case presentation}

67 years old male patient was taken for a knee arthroscopy for his gonarthrosis. He had a history of hyperlipidaemia and enlarged prostate. He had surgery for protrusion of the intervertebral disc L4-L5 and bile surgery 40 years ago. His body mass index (BMI) is $28.4 \mathrm{~kg} / \mathrm{m}^{2}$.

The procedure was made under spinal (subarachnoid) anaesthesia. Arthroscopy was made with a pressure pump with pressure of $50 \mathrm{mmHg}$.
During the procedure he was hemodynamically stable, towards the end of the procedure he suddenly turned pale and started complaining of severe pain in the lower abdomen on the left side; clinically developing signs of guarding. Nasogastric tube was placed, only the gastrointestinal-bile contents were obtained in trace amounts. Hemodynamically he was still stable (140/80 $\mathrm{mmHg})$. Tourniquet was working for 45 minutes before onset of described symptoms.

The procedure was completed as quickly as possible. After releasing the tourniquet, initially set at $250 \mathrm{mmHg}$, a significantly larger volume of the left leg was noted when compared to the right one, and there was redness distal to the tourniquet position. Urgent radiological diagnostics was requested with a differential diagnosis of hollow organ rupture or thromboembolic event. Abdominal X-ray in lateral decubitus position and Colour Doppler (CD) of the left leg showed fluid in the soft tissues of the thigh, scrotum, and abdomen; non enhanced and contrast enhanced, venous phase computed tomography (CT) of the abdomen and pelvis showed a free fluid along the entire left thigh around the femoral shaft, extending towards the scrotum, gluteal region, into the pelvis, and into the abdomen. Fluid was present in 
the perihepatic and perisplenic spaces with gas bubbles in the left retroperitoneum and anterior aspect of the left thigh.

He was admitted to the Intensive care unit (ICU) for noninvasive monitoring: blood pressure (BP) $120 / 80$, pulse $70 /$ min, Sp02 99\%, breathing frequency (BF) 19/min. Heart and lung sounds were normal, abdomen was painless, and peristalsis was audible. Left foot was oedematous with good peripheral pulsation, right foot was unremarkable.

The patient was pale and hypothermic, emergency lab was within a normal range, except for moderate compensated metabolic acidosis (bicarbonates 17 , base excess - 7.9, lactates 1.6) (Figures 1-7).

He was hemodynamically stable, excess fluid was resorbed and excreted by stimulated diuresis and all of the

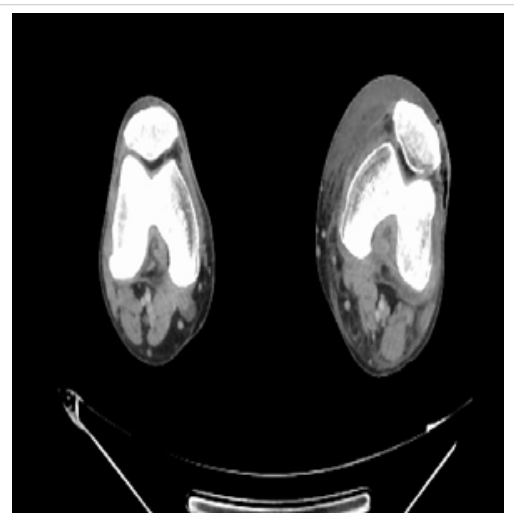

Figure 1: Patellar.

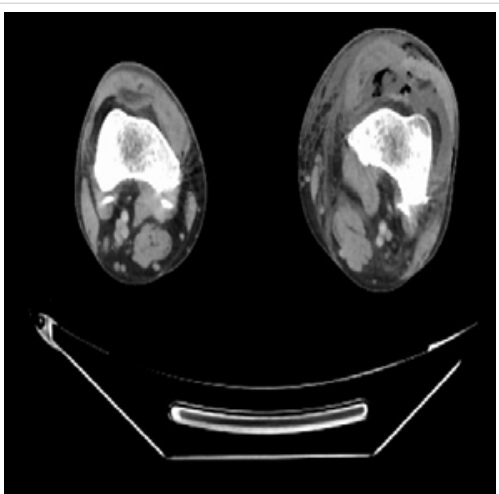

Figure 2: Theigh

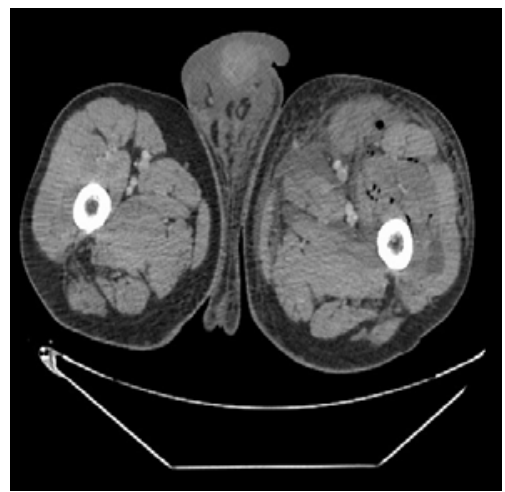

Figure 3: Upper theigh and scrotum.

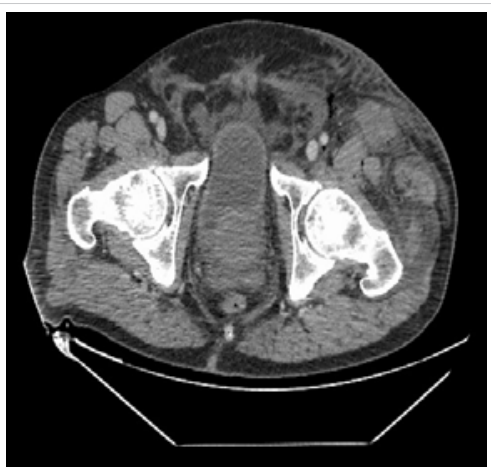

Figure 4: Hips and lower pelvis.

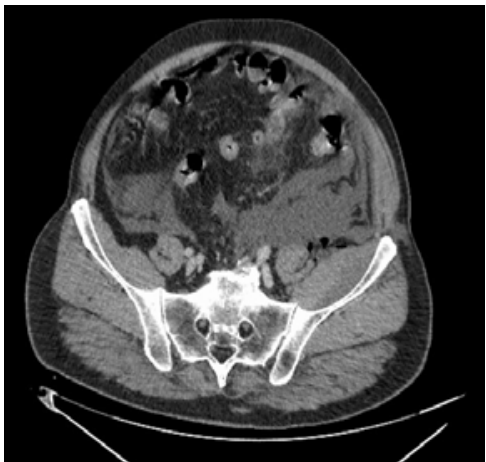

Figure 5: Pelvis.

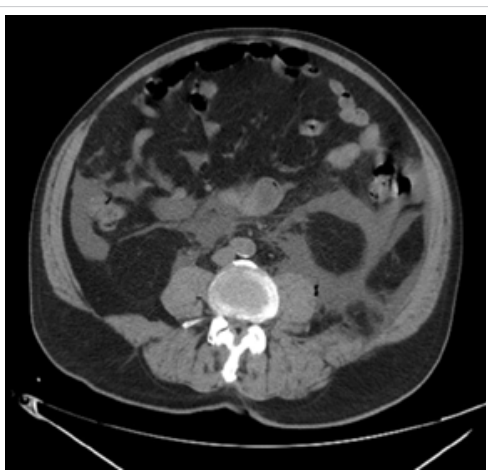

Figure 6: Abdomen

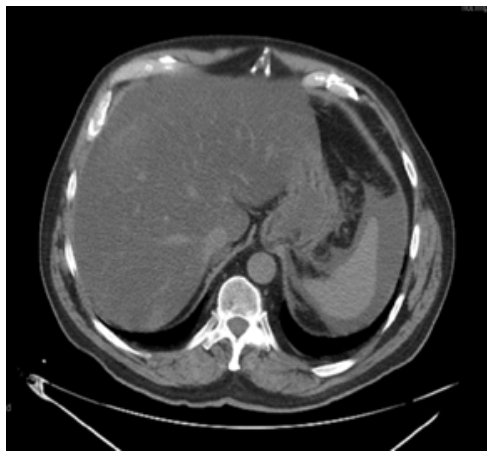

Figure 7: Abdomen: transhepatic/transsplenic cross section.

symptoms resolved within a few hours after the surgery. In the end it turned out that symptoms of acute abdomen were caused by accumulation of fluid in abdomen cavity and retroperitoneum. The patient was transferred to the ward the following day and his postoperative course was uneventful, without further complications. 


\section{Discussion}

We hadn't had a complication like the one we described here, so we consulted all available literature to determine the cause. The available literature shows only a few similar cases, of which most of them did not use the tourniquet at all [2,3]. In most of other described cases, there was a compartment syndrome distal to the site of the tourniquet $[4,5]$. Abdominal extravasation of irrigation fluid was mostly described after hip arthroscopy [6].

As the symptoms of acute abdomen occurred, we tried to visualise if there is any sign of knee capsule rupture, or any sign of some other complication, but we couldn't visualise it with arthroscope. Scrub nurse observed sudden larger saline consumption by the pump, but the pump stated the same pressure set on the beginning of the procedure, so the real cause of the symptoms was not confirmed. We checked arthroscopic pump and all parts of tourniquet formal functions, but we couldn't find any, all parts of the equipment passed the control.

\section{Conclusion}

Inclusive; this complication was presumably caused by a ruptured knee capsule, although we couldn't see it with arthroscope nor imaging tests, but since both radiographic methods described both liquid and gas within the leg proximally of the knee capsule and within the abdomen, it is the only conclusion we could make. In most cases in literature, the main cause of fluid extravasation was rupture of the capsule caused by a pressure sensor failure [2,3,7].

Whether the cause of the rupture is a faulty arthroscopic pump or something else, we cannot say with certainty (both were tested after the procedure, but we didn't find any malfunctions).

We learned that this might have been avoided if we monitored liquid balance all the time during the procedure (output should be almost equal as input) in arthroscopy more closely; therefore, we would recommend it as one of the safety measures.

In our opinion, it was fortunate we performed this arthroscopy in spinal (subarachnoid) anaesthesia, because the patient was awake and could alert us of something unexpected happening; should general anaesthesia been used, the consequences would probably be worse due to larger amount of fluid which would have been used before anything would have been noticed.

\section{References}

1. Friberger Pajalic K, Turkiewicz A, Englund M. Update on the risks of complications after knee arthroscopy. BMC Musculoskelet Disord. 2018; 19: 179.

PubMed: https://pubmed.ncbi.nlm.nih.gov/29859074/

2. Bomberg BC, Hurley PE, Clark CA, McLaughlin CS. Complications associated with the use of an infusion pump during knee arthroscopy. Arthroscopy. 1992; 8: 224-228.

PubMed: https://pubmed.ncbi.nlm.nih.gov/1637436/

3. Romero J, Smit CM, Zanetti M. Massive intraperitoneal and extraperitoneal accumulation of irrigation fluid as a complication during knee arthroscopy. Arthroscopy. 1998; 14: 401-404. PubMed: https://www.ncbi.nlm.nih.gov/pmc/articles/PMC3671121/

4. Belanger $M$, Fadale P. Compartment syndrome of the leg after arthroscopic examination of a tibial plateau fracture: case report and review of the literature. Arthroscopy. 1997; 13: 646-651. PubMed: https://pubmed.ncbi.nlm.nih.gov/9343658/

5. Marti CB, Jakob RP. Accumulation of irrigation fluid in the calf as a complication during high tibial osteotomy combined with simultaneous arthroscopic anterior cruciate ligament reconstruction. Arthroscopy. 1999; 15: 864-866.

PubMed: https://pubmed.ncbi.nlm.nih.gov/10564866/

6. Fowler J, Owens BD. Abdominal compartment syndrome after hip arthroscopy. Arthroscopy. 2010; 26: 128-130. PubMed: https://pubmed.ncbi.nlm.nih.gov/20117637/

7. Cavaignac E, Pailhé R, Reina N, Chiron P, Laffosse JM. Massive Proximal Extravasation as a Complication during Arthroscopic Anterior Cruciate Ligament Reconstruction. Knee Surg Relat Res. 2013; 25: 84-87.

PubMed: https://www.ncbi.nlm.nih.gov/pmc/articles/PMC3671121/ 